\title{
A Educação Integral \\ na Região Sul do Brasil
}

\section{Integral Education}

In the South Region of Brazil

La Educación Integral

en la región sur de Brasil

ROSA MARIA BORTOLOTTI DE CAMARGO*

Universidade Federal de Santa Maria, Santa Maria, RS. Brasil.

ROSANE CARNEIRO SARTURI**

Universidade Federal de Santa Maria, Santa Maria, RS. Brasil.

MÔNICA DE SOUZA TREVISAN***

Universidade Federal de Santa Maria, Santa Maria, RS. Brasil.

\begin{abstract}
RESUMO: A Meta 6 do Plano Nacional de Educação (PNE) referente a oferta de educação em tempo integral (BRASIL, 2014) é o foco neste artigo. A pesquisa foi quanti-qualitativa, com busca realizada no Observatório do PNE e no Instituto Nacional de Estudos e Pesquisas Educacionais Anísio Teixeira, sobre a oferta de Educação Integral (EI) nos Estados da RegiãoSul do Brasil. A EI é uma proposta educacional complexa, que vem sendo interpretada como o aumento quantitativo da jornada escolar e incentivada por programas de governo.
\end{abstract}

* Pedagoga pela Universidade Federal de Santa Maria. Atualmente é mestranda em Educação pelo Programa de Pós-Graduação em Educação da UFSM e integrante do Grupo de Pesquisa "Interlocuções entre políticas públicas e ações pedagógicas: limites e possibilidades" (ELOS) da UFSM. E-mail: <bortolottidecamargorosamaria@outlook.fr>.

** Mestre em Educação pela Universidade Federal de Santa Maria e Doutora em Educação pela Universidade Federal do Rio Grande do Sul. É professora Associada III da Universidade Federal de Santa Maria no Departamento de Administração Escolar, atuando na graduação e no Programa de Pós-Graduação em Educação, do Centro de Educação da UFSM. E-mail: <rcsarturi@gmail.com>.

*** Técnica Administrativa em Educação na Universidade Federal do Pampa, no cargo de Pedagoga. Mestre pelo Programa de Pós-Graduação em Educação da Universidade Federal de Santa Maria, mesma instituição onde atualmente é Doutoranda em Educação. E-mail:<monicastrevisan@gmail.com>. 
Palavras-chave: Educação integral. Plano Nacional de Educação. Programas de governo.

Abstract: The Sixth Goal of the National Plan for Education (PNE) regarding the provision of full-time education (BRASIL, 2014) is the focus of this article. The research was quantitative-qualitative, with a quest conducted at the PNE Observatory and the Anísio Teixeira National Institute of Educational Studies and Research, on the offer of Integral Education (EI) in the states of the southern region of Brazil. EI is a complex educational proposal that has been interpreted as the quantitative increase of the school day and is encouraged by government programs.

Keywords: Integral education. National Education Plan. Government Programs.

RESUMEN: La Meta 6 del Plan Nacional de Educación (PNE) con respecto a la provisión de educación a tiempo completo (BRASIL, 2014) es el enfoque de este artículo. La investigación fue cuantitativa y cualitativa, con una búsqueda realizada en el Observatorio del PNE y en el Instituto Nacional de Estudos e Pesquisas Educacionais Anísio Teixeira, sobre la provisión de Educación Integral (IE) en los estados del sur de Brasil. La EI es una propuesta educativa compleja, que se ha interpretado como un aumento cuantitativo en la jornada escolar e incentivada por los programas de gobierno.

Palabras clave: Educación integral. Plan Nacional de Educación. Programas de gobierno.

\section{Introdução}

E ste artigo é fruto de uma análise quanti-qualitativa dos resultados apresentados pelo Observatório do Plano Nacional da Educação sobre a meta 6 do Plano Nacional de Educação (PNE) aprovado pela Lei no 13.005, de 25 de junho de 2014 (BRASIL, 2014). A meta estabelece: “Oferecer Educação em tempo integral em, no mínimo, 50\% das escolas públicas, de forma a atender, pelo menos, 25\% dos alunos da Educação Básica" (BRASIL, 2014). Conforme estabelecido pelo Plano, a referente meta deve ser alcançada até 2024 . 
O PNE é um conjunto de metas e objetivos elaborados para serem alcançados pelo País, seus estados e municípios no desenvolvimento da educação pública. No que se refere à história do PNE, este é o segundo aprovado em formato de lei no Brasil. Anterior a ele, houve o PNE de 2001-2011, aprovado pela Lei n 10.172, de 9 de janeiro de 2001 (BRASIL, 2001). Antes de 2001, houve planos e metas debatidos e escritos, mas sem o caráter de lei, e se configuravam mais como projetos de mudança na educação pública ${ }^{1}$. Após 2001, os objetivos e metas do PNE são tomados como responsabilidade das esferas administrativas.

Deste modo, coube a todos os estados, municípios e Governo Federal buscar os meios para se adequar ao processo de aplicação das metas e objetivos estabelecidos pelo PNE, com sua vigência prevista de dez anos, até 2011, munido de 26 objetivos.

Três anos mais tarde, o PNE 2014-2024 foi aprovado pela Lei ${ }^{\circ} 13.005$ de 25 de junho de 2014 (BRASIL, 2014), o segundo grande Plano Nacional de Educação do País. O Plano estabelece vinte metas e tem como objetivo principal determinar diretrizes, metas e estratégias para a política educacional brasileira no período de dez anos.

Para este artigo, apresentaremos a análise realizada pelo Observatório referente à Meta 6, do PNE 2014-2024, que trata da Educação Integral (EI) nas escolas públicas. Sendo um desafio histórico do País, o alargamento da carga horária diária escolar pública e a qualificação dos tempos e espaços escolares ainda não é total: pouco mais da metade das escolas possuem um regime de funcionamento intitulado integral. Não obstante, no campo prático, diversos desafios estruturais e de financiamento suscitam os questionamentos: que tipo de integralidade vem sendo posta em prática nas escolas públicas que possuem regime de jornada diária escolar expandida? Quais escolas efetivamente se beneficiam de uma jornada escolar ampliada?

Optamos por uma metodologia quanti-qualitativa na medida em que tendemos a complementar as abordagens de acordo com Sampieri, Collado e Lucio (2013); os problemas complexos que a ciência se depara prescindem de métodos complementares para trabalhar essa complexidade. Isso possibilitou observar o caminho percorrido pela EI até o momento, ancorados na análise de documentos, leis e dados quantitativos, buscando refletir e questionar acerca desse panorama.

Sendo assim, este artigo está dividido em três partes: a primeira seção contextualiza a história da EI no País e o que ela representa atualmente para a escola pública brasileira, com uma pesquisa bibliográfica e documental, a partir dos autores que estudam educação integral e dos documentos legais que tratam do tema. Na segunda seção, apresentamos os dados quantitativos coletados no site Observatório do Plano Nacional de Educação e no Instituto Nacional de Educação e Pesquisas Educacionais Anísio Teixeira (Inep) sobre o número de escolas que possuem jornada escolar integral na Região Sul do País, compreendendo os estados do Paraná (PR), Rio Grande do Sul (RS) e Santa Catarina (SC). Por fim, as nossas considerações finais sobre a pesquisa realizada e as reflexões acerca da temática da EI. 


\title{
A EI no Brasil: uma longa história
}

No século XX, os pioneiros da Educação Nova ganham notoriedade por serem os primeiros profissionais da educação que de fato exigiram reformas para o sistema de ensino brasileiro. $\mathrm{O}$ movimento foi considerado pioneiro, também, por pensar em um projeto nacional de educação.

É, justamente, um dos principais autores deste movimento, o educador Anísio Teixeira (1900-1971), que propôs os primeiros projetos de EI ou tempo integral (TI) de escola pública, considerados a primeira referência do tema no País. O educador, embora tenha feito pouco uso do termo EI (PORTUGAL; SOARES; MOREL; CAVALIERE, 2015), propôs, nos anos 30, uma reforma educativa alicerçada sob a ideia da transformação da escola pública não somente em um espaço de aprendizagem de conteúdos, mas, também, em um espaço de formação humana para a vida em sociedade. Para isso, basicamente, seria necessário alargar quantitativamente o tempo de escola e, ao mesmo tempo, qualificar as atividades desenvolvidas pelas crianças nesse tempo. Aulas de formação profissional, de atividades físicas e alimentação eram alguns dos aspectos previstos.

Teixeira propôs para o estado da Bahia, onde ele foi secretário da Educação², um modelo de escola chamado Escola-Parque. Ele pretendia construir uma escola única, fundada sob os preceitos de uma educação total da criança e do jovem. Seu objetivo maior era diminuir a desigualdade escolar e social entre crianças ricas e pobres através da oferta de uma formação integral para as crianças pobres, oferecendo desde aulas tradicionais até formação extra, com oficinas e atividades diferenciadas para as crianças.

Conforme Portugal; Soares; Moraes; Cavaliere (2015), para Anísio Teixeira a escola não poderia mais ser vista como um espaço isolado da sociedade, pois ela tendia a ser desigual na medida em que educava as crianças pobres em um único período escolar, enquanto as crianças oriundas de famílias mais abastadas podiam obter outras experiências para além da escola,

\begin{abstract}
Anísio Teixeira desenvolve sua concepção de educação escolar ampliada e defende o horário integral, pensando em uma nova política educacional que levasse qualidade para a escola primária e a transformasse em uma escola para todos. A escola primária não poderia ser uma escola de tempo parcial, na medida em que estaria envolvida na formação de hábitos de pensar e fazer, de conviver e participar de uma sociedade democrática. (PORTUGAL; SOARES; MOREL; CAVALIERE, 2015, p: 530).
\end{abstract}

Uma educação em tempo integral seria, portanto, capaz de educar as crianças e jovens para além dos componentes curriculares tradicionais, ou seja, para a vida adulta e em sociedade. Visto que a sociedade brasileira era (é) uma sociedade maioritariamente desigual, na qual a escola de tempo integral seria uma forma de fazer com que a criança pobre pudesse socializar-se com conhecimentos e atividades que ela estava restrita de conhecer no seu espaço de vida fora da escola. A proposta de escola integral se inscrevia, 
portanto, no reparo dos processos de segregação e desigualdade social dos séculos anteriores, ou seja, uma grande massa de população pobre e iletrada necessitava de uma educação muito mais ampla e digna, ampliando as possibilidades de formação e melhorando a qualidade da educação até aquele momento.

A partir da experiência de Anísio Teixeira, muitas foram as propostas de reformar a escola brasileira. Nas décadas de 1980 e 1990, houve movimentos importantes sobre o tema. Conforme Cordeiro (2001), a experiência de Anísio Teixeira inspirou a construção de dois grandes projetos de EI. O primeiro foi o da construção do Centros Integrados de Educação Pública (Ciep) na década de 80 a partir de Darcy Ribeiro. Eles se expandiram, principalmente, no Rio de Janeiro, pois Darcy Ribeiro foi vice-governador do estado, aonde foram criadas mais de 500 escolas de tempo integral (CAVALIERE, 2007). Outra experiência foi a dos chamados Centros Integrados de Atendimento à Criança (Ciac), posteriormente renomeados como Centro de Atenção Integral à Criança e Adolescente (Caic).

Os Ciep foram criados com o objetivo de ser escolas que proporcionassem, além das aulas tradicionais do currículo, atividades de esportes e culturais, assistência médica (dentistas, psicólogos e enfermeiros se destacam). Para isso, as escolas obedeciam a um projeto arquitetônico uniforme a partir de uma mesma estrutura e modelo. Cavaliere (2007), em seu artigo “Tempo de escola e qualidade na educação pública”, mostra diversos modos de implementação dos Ciep em vários estados brasileiros. Não obstante, a autora ressalta que a maior parte deles não conseguiu continuar trabalhando a partir da proposta original, ofertando todas as atividades extras ao currículo tradicional escolar, devido a diferentes dificuldades financeiras e estruturais para manter a demanda de alunos em turno integral em todo o país ${ }^{3}$.

Ainda no fim do século XX, havia um considerável número de crianças que estavam mais na rua do que na escola, os "meninos de rua" assim chamados eram constatados na década de 1990. Na tentativa de minimizar esse problema, foi criado o Projeto Minha Gente pelo Governo Federal como uma proposta de assistência social. Esta proposta previa a construção de unidades físicas dos intitulados Centros Integrados de Atenção à Criança e ao Adolescente (Ciac) por todo o território brasileiro (SOBRINHO; PARENTE, 1995). As escolas seriam construídas, a partir de um modelo padrão, ofertando, além das aulas tradicionais do currículo escolar, o atendimento à saúde, assistência e promoção social. Essas atividades, assim como no Ciep, estavam voltadas para as crianças oriundas dos meios sociais menos favorecidos (SOBRINHO; PARENTE, 1995).

Se futuramente a proposta do Ciac, por uma questão de reorganização das responsabilidades de efetivação do Projeto Minha Gente, teve sua nomenclatura modificada para Caic (Centro de Atenção à Criança e Adolescente), o que ficou claro era que seu funcionamento tinha como público alvo crianças oriundas da classe popular, e como meta promover uma escola capaz de oferecer uma totalidade de ações que contribuíssem para o cuidado, assistência e atenção de crianças e jovens. 
Contudo, estas propostas de incentivo a uma escola de tempo integral nunca tiveram continuidade e legitimidade na política pública educacional brasileira. Conforme Mignot (2001), ainda que apontadas como a solução para os males da educação e das desigualdades sociais, elas também pareciam ser as vilãs, uma vez que as propostas eram reduzidas a um número específico de alunos, demandavam uma grande quantidade de investimento financeiro e estavam limitadas em alguns estados e cidades, portanto, eram descontínuas. Dos modelos apresentados, atualmente, o que restou foram somente as estruturas físicas construídas, possivelmente funcionando como escolas regulares com turnos de quatro horas.

Em 2007, o Ministério da Educação (MEC) apresentou o programa Mais Educação, sob o conceito de EI e com a estratégia de promoção de um modelo educacional pelo qual a criança passaria mais horas na escola. Este programa propôs diferentes atividades às crianças depois do tempo de aula obrigatório (no turno inverso). Pela organização do Mais Educação, a criança desenvolvia atividades extraescolares regidas por diferentes profissionais de diversas áreas de conhecimento.

Ademais, os critérios de seleção das crianças participantes do projeto estavam versados em indicadores sociais visando as crianças pobres (público alvo do projeto), e as escolas que apresentassem um coeficiente de desempenho escolar abaixo da média proposta pelo sistema de avaliação nacional que mede o Índice de Desenvolvimento da Educação Básica $(\mathrm{Ideb})^{4}$. Contudo, como o programa não se concretizou como política pública, mas sim uma estratégia de desenvolvimento e encorajamento para a aplicação de uma escola de tempo integral, a garantia de abrangência e atendimento do programa não foi precisa.

Agrega-se que o funcionamento do Mais Educação dependia da conjuntura econômica do país e dos repasses feitos pela União e, sobretudo, através do Programa Dinheiro Direto na Escola (PDDE). A partir de 2015, o Programa mudou de nome e se intitula atualmente "Novo Mais Educação". Resumidamente, a proposta se apresenta como a readaptação da antiga, mas com menos investimento em atividades culturais, artísticas e prioridades na oferta de aulas de reforço em português e matemática no contra turno escolar ${ }^{5}$.

A apresentação desses exemplos sobre múltiplas propostas de EI ao longo do tempo evidenciam que a problemática da EIno país está ligada a projetos que encorajam as escolas públicas, por meio de incentivo financeiro, a desenvolver uma proposta de EI. Não obstante, tais projetos ainda são descontínuos, não são aplicados de forma efetiva e nacional como política pública para todas as crianças em todas as escolas públicas. Vimos, assim, que os projetos existiram na medida que haviam fundos e interesses políticos e o atual PNE 20142024 caminha em passos lentos no avanço de suas metas.

Logo, podemos pensar que a ampliação do tempo escolar ainda é um desafio quanti-qualitativo, pois a expansão do ensino necessita de investimentos que vão desde a ordem financeira quanto da formação de professores, construção de espaços educativos e de novas escolas. Ademais, o País não consegue proporcionar condições para que as escolas públicas 
ofertem mais que as 4h diárias, respeitando, assim, a distribuição das 800 horas com os 200 dias letivos previstos obrigatoriamente em lei ${ }^{6}$.

A atual configuração do tempo de escola pública tradicional brasileira tem aulas desenvolvidas tanto nos turnos da manhã quanto da tarde. Normalmente, no turno inverso, a mesma escola que recebe as crianças dos anos iniciais dispõe de seu espaço para que os alunos da seguinte etapa, os anos finais do ensino fundamental, tenham aula. A organização mais comum do tempo escolar no Brasil é de que as turmas da etapa dos anos iniciais tenham aula entre as $8 \mathrm{~h}$ e às $12 \mathrm{~h}$ e os alunos dos anos finais do ensino fundamental entre as $13 \mathrm{~h}$ e às $17 \mathrm{~h}$ ou vice e versa 7 .

Entendemos que as últimas propostas de encorajamento de aumento do tempo escolar estiveram, em muitos casos, isoladas, e foram sempre configuradas como políticas de Governo desenvolvidas por programas descontinuados. Logo, a reflexão que se faz necessária é de que o debate sobre a jornada escolar ampliada ou a EI deve ultrapassar propostas eleitorais e ser, de acordo com Arroyo (2012), uma política de Estado que garanta não somente mais tempo compulsório de escola, mas, também, direitos de aprendizagem. Direitos básicos e dignos para que as crianças e jovens da periferia desfrutem de mais tempo de atividades, de relação com conhecimentos, de experiências em espaços e tempos lúdicos e harmoniosos. Mais que isso, a EI prescinde de uma organização escolar democrática e, sendo assim, um modelo de escola abrangente para acolher todos os alunos das diferentes classes sociais frequentadores da escola pública.

Nosso segundo objetivo nesse artigo é mostrar o que já vem sendo feito em termos quantitativos nas escolas da Região Sul do País, através das informações disponíveis no Observatório do PNE e no Inep.

\section{EI no Brasil: as plataformas governamentais}

Diversas propostas visando a integralidade na educação foram desenvolvidas ao longo dos anos no Brasil. Vale ressaltar que não desenvolvemos nesse artigo estudos que pautam sobre as proposições de atendimento de crianças no turno extraescolar, ou no contra turno da escola, que são frutos de incentivos privados e/ou organizações filantrópicas e religiosas as quais acolhem as crianças, sobretudo de regiões carentes, de forma gratuita.

Nesta seção mostraremos como vem se desenvolvendo as propostas de EI nas escolas públicas da Região Sul do País, compreendendo os estados do Paraná (PR), Rio Grande do Sul (RS) e Santa Catarina (SC). Realizamos nossa pesquisa em duas plataformas governamentais, o Observatório do PNE e o Instituto Nacional de Estudos e Pesquisas Educacionais (Inep). A delimitação territorial proposta parte de um entendimento de que, tendo em vista a grandiosidade do Brasil, é necessário delimitar os dados a fim de mostrar um panorama da nossa região. 
Sendo assim, os estados localizados na Região Sul totalizam 27.386.891 habitantes, sendo 10.693.929 para o RS, 10.444.820 para o PR e 6.248.436 para SC. No ranking de estados e população, ambos ocupam respectivamente a $5^{\mathrm{a}}$, $6^{\mathrm{a}}$ e $11^{\underline{a}}$ posição segundo $\mathrm{o}$ Instituto Brasileiro de Geografia e Estatística (IBGE, 2017).

Considerando as matrículas de tempo integral nos anos iniciais, nos direcionamos até o site do Observatório do PNE. Na pesquisa realizada, foi possível perceber que não há uma separação sobre o número de alunos matriculados por etapas da educação básica (EB), ou seja, anos iniciais (AI), os anos finais (AF) e ensino médio (EM) mas, somente, um valor correspondente ao número de escolas que ofertam educação em tempo integral em toda a etapa EB.

Assim, ficou inviável calcular através dos dados fornecidos pelo Observatório do PNE a que nível educacional se referiam os números de matrículas disponibilizados no site. O valor que nos fornece o Observatório é de que, até 2014,42\% das escolas da EB, no Brasil, tinham um regime de EI. Segundo o Observatório, esse valor corresponde à 62.575 escolas brasileiras (OBSERVATÓRIO DO PNE, 2014). Assim, a investigação levantada no site deixou algumas questões em aberto: quais escolas está mencionando o Observatório do PNE? E a quais matrículas os dados ali fornecidos se referem?

Sobre os três estados que pesquisamos, no que corresponde o número de escolas públicas da EB que ofertam o tempo integral, o Observatório (2014) apresenta as seguintes porcentagens: 50,08\% (3.812 escolas), no RS, 52,5\% (3.785 escolas) no PR e 53,4\% (2.786 escolas) em SC. Esses valores correspondem a escolas que ofertam tempo de mais que quatro horas diárias de escola formal. Não obstante, vale ressaltar que encontramos incoerência de informações sobre o número de escolas no Observatório do PNE e o Inep e que, mais uma vez, não há precisão sobre quais etapas da educação básica se remetem os dados do Observatório. Tal condição nos levou a buscar informações mais concisas no site do Inep.

Nos cálculos aproximativos que realizamos para conferir se a quantidade de escolas e as porcentagens fornecidas pelo Observatório correspondiam às do Inep, não conseguimos chegar à mesma quantidade de escolas nas duas plataformas.

Sendo assim, se por exemplo sabíamos, segundo os dados fornecidos pelo Observatório, que o número de escolas da EB em tempo integral no RS era de 3.812 escolas, ou seja 50,08\%, logo, o valor total aproximativo de 100\% de escolas seria de 7.611 escolas ${ }^{8}$. Não obstante, o Inep nos forneceu o valor de 7.481 escolas públicas ${ }^{9}$, ou seja, há uma diferença de 130 escolas que foram computadas ou não e as quais não saberíamos determinar. No caso do PR, o valor de 52,5\% correspondia à 3.785 escolas, logo, 100\% das escolas seria em média 7.209 escolas. No Inep o valor é de 7.348, logo, uma diferença de 139 escolas. Por fim, no de SC o valor de 53,4\% é de 2.786 escolas logo, 100\% é de 5.217 escolas, mas, no Inep, o valor fornecido é de 5.303, outra vez uma diferença de 86 escolas. Abaixo o gráfico das quantidades: 


\section{Gráfico 1 - Número de escolas Observatório PNE x INEP}

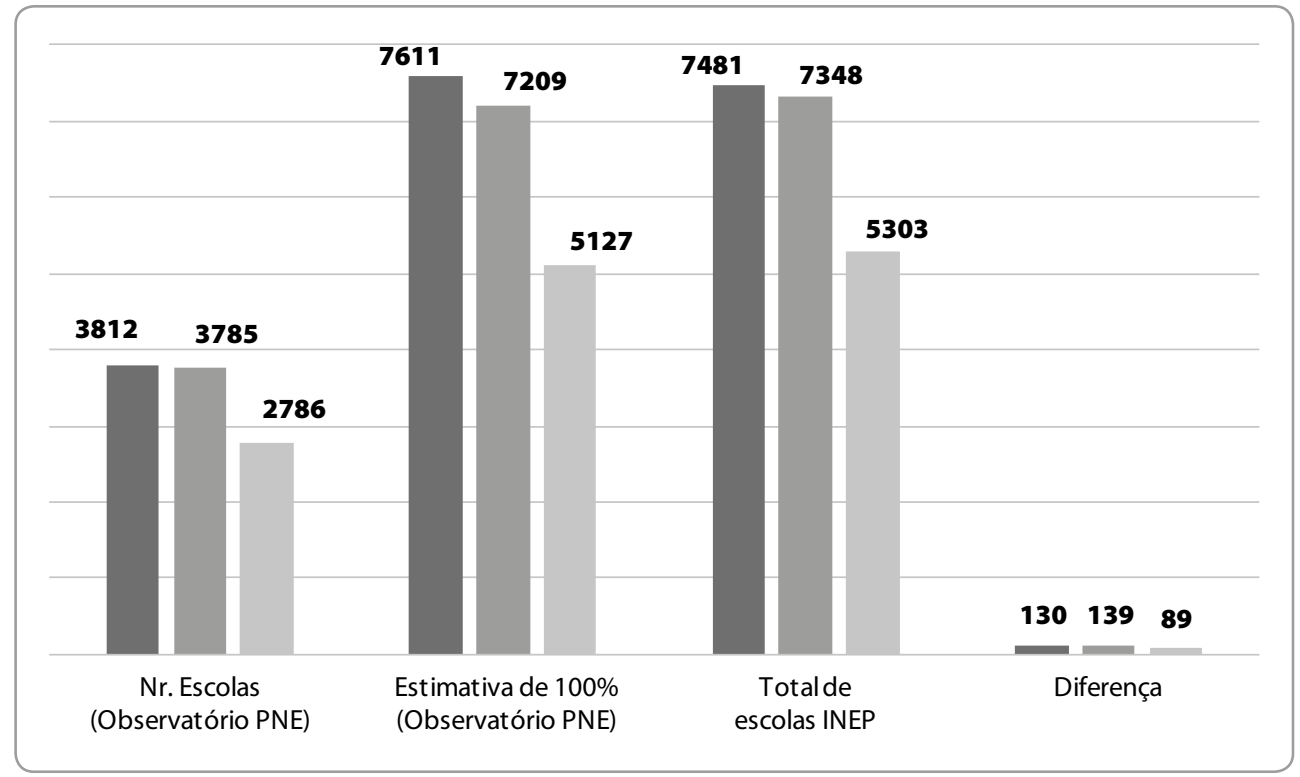

Fonte: Elaborado pelas autoras (INEP, 2017 / OBSERVATÓRIO DO PNE 2014). Azul: RS. Laranja: PR. Cinza: SC.

Por fim, consideramos que não seria possível chegar a uma conclusão sobre a objetividade da Meta 6, analisando as informações sobre número de escolas fornecidas pelo Observatório do PNE. Entendemos que havia uma incoerência de informações, seja pelo fato de que o site não está atualizado, seja porque os dados contabilizados não conferem com as informações fornecidas pelo Censo Escolar. O número de escolas em situação de tempo integral que contabilizam os $42 \%$ da meta atingida, de acordo com a plataforma do Observatório do PNE, é de 2014.

Sendo assim, lançamos uma outra análise na tentativa de entender especificamente o que vem ocorrendo quanto a expansão da escola pública em tempo integral no percurso da educação básica, considerando educação infantil e ensino fundamental. Direcionamos nossa atenção às estatísticas fornecidas no Censo Escolar do ano de 2016 realizado pelo Inep.

O gráfico a seguir aponta o total de matrículas em 2016, na EB, nos três estados da Região Sul, considerando o total de matrículas, sem discriminação entre as redes pública e privada e entre os níveis de ensino: 
Gráfico 2 - Total de matrículas na Educação Básica

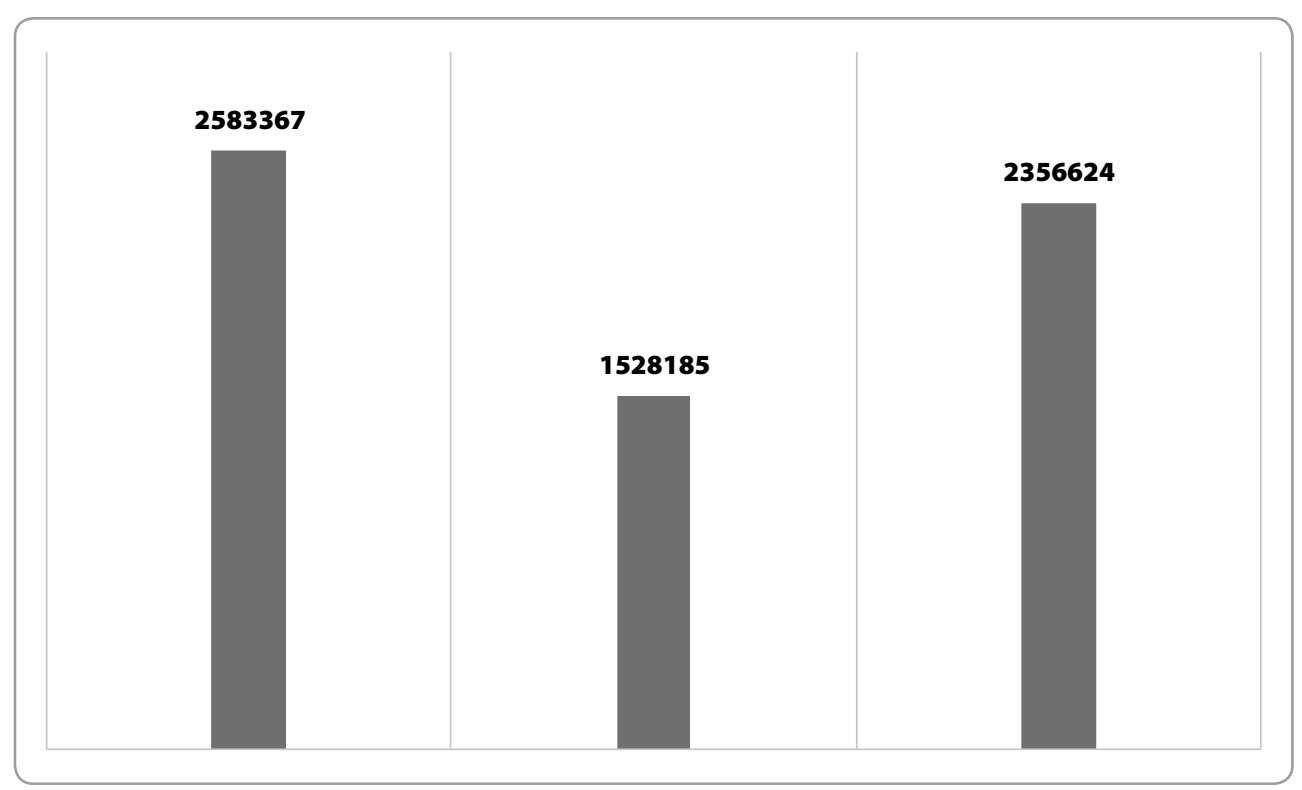

Fonte: Elaborado pelas autoras Fonte: Elaborado pelas autoras com base na Sinopse Estatística da Educação Básica 2016 (INEP, 2017).

Já a tabela abaixo, apresenta o número total de matrículas em 2016 nos três estados, discriminando os três níveis da educação básica. Esses dados também não diferenciam matrícula em estabelecimento público ou privado,

Tabela 1 - Número total de matrículas em 2016 em PR, SC, RS.

\begin{tabular}{|c|c|c|c|c|c|c|}
\hline & \multicolumn{3}{|c|}{ Educação Infantil } & \multicolumn{3}{|c|}{ Ensino Fundamental } \\
\hline & Total & Creche & Pré-Escola & Total & $\begin{array}{l}\text { Anos } \\
\text { Iniciais }\end{array}$ & $\begin{array}{l}\text { Anos } \\
\text { Finais }\end{array}$ \\
\hline PR & 444.236 & 211.696 & 232.540 & 1.447.195 & 801.251 & 645.944 \\
\hline SC & 338.541 & 163.409 & 175.132 & 838.179 & 457.017 & 381.162 \\
\hline RS & 411.362 & 179.386 & 231.976 & 1.338 .719 & 725.732 & 612.987 \\
\hline
\end{tabular}

Fonte: Elaborado pelas autoras com base na Sinopse Estatística da Educação Básica 2016 (INEP, 2017).

Após apresentado o número de matrículas em ambos os estados, nos aprofundamos em coletar os dados relacionados nas etapas da EB desde a educação infantil até o ensino fundamental às matrículas em tempo integral e, posteriormente, cruzamos tais dados com a matrícula em tempo parcial. Nessa segunda parte da investigação, consideramos somente as matrículas na rede pública, seja ela federal, estadual ou municipal. 
É importante destacar que, nos gráficos a seguir, optamos por apresentar, também, os dados que contabilizam matrículas da educação especial.

Para os dados gerados pelo Censo Escolar existem especificações que diferenciam o horário de funcionamento das escolas. Elas se intitulam: tempo integral e tempo parcial. Para tempo integral, o Censo Escolar entende que são aquelas em que os alunos estão em turmas presenciais com sete ou mais horas de duração, bem como os que estão em turmas presenciais com carga horária menor, mas que, somada com o tempo de atividade complementar no turno extraescolar, atinja as sete horas ou mais de atividades. Para tempo parcial, entende-se os alunos que não estão em turmas presenciais com sete ou mais horas de duração e/ou os alunos de turmas do ensino à distância (EAD). Assim sendo, utilizamos como abreviatura TI (Tempo Integral) e TP (Tempo Parcial). A seguir, as matrículas em TI na educação infantil.

Gráfico 3 - Número de matrículas em TI na etapa da Educação Infantil

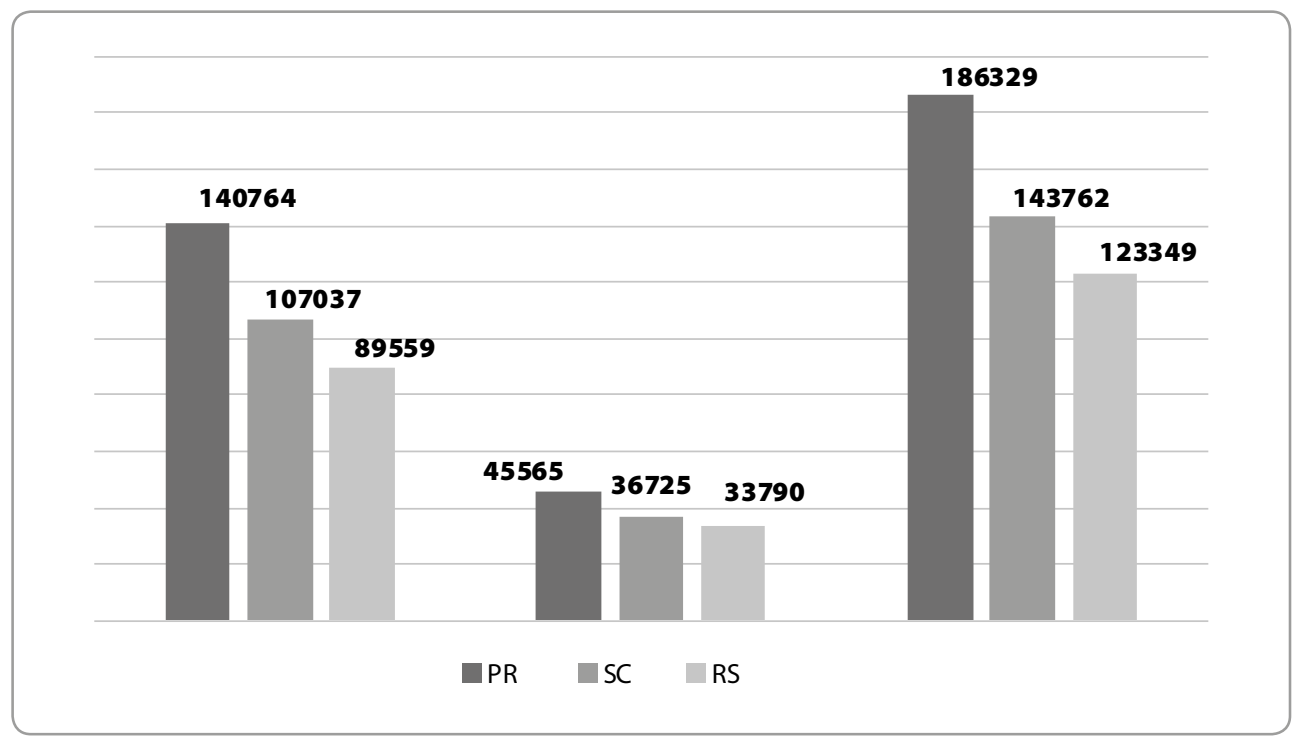

Fonte: Elaborado pelas autoras com base na Sinopse Estatística da Educação Básica 2016 INEP (2017).

Agora, os dados do ensino fundamental, também considerando apenas a matrícula em TI. 
Gráfico 4 - Número de matrículas em TI no Ensino Fundamental

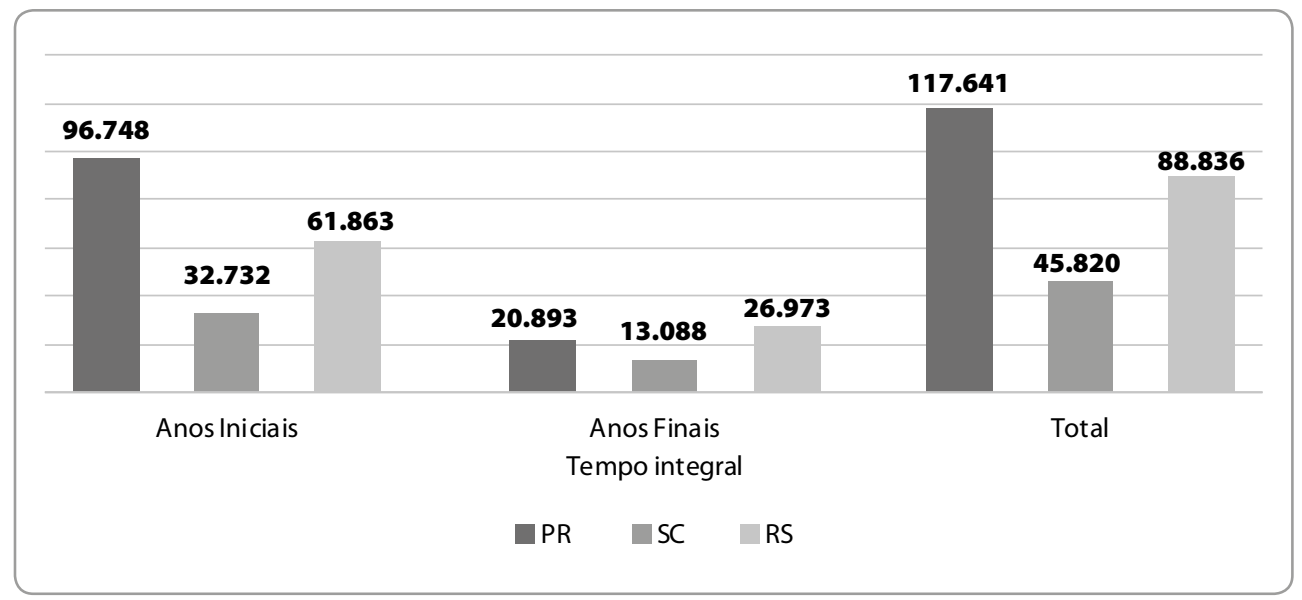

Fonte: Elaborado pelas autoras com base na Sinopse Estatística da Educação Básica 2016 (INEP, 2017).

A seguir, cruzamos os dados da matrícula em TI com a matrícula em TP, considerando as mesmas tabelas da Sinopse Estatística do Inep, sendo possível comparar, em cada etapa, o número de matrículas de tempo integral e parcial.

\section{Gráfico 5 - Número de matrículas em tempo integral e parcial na Educação Infantil}

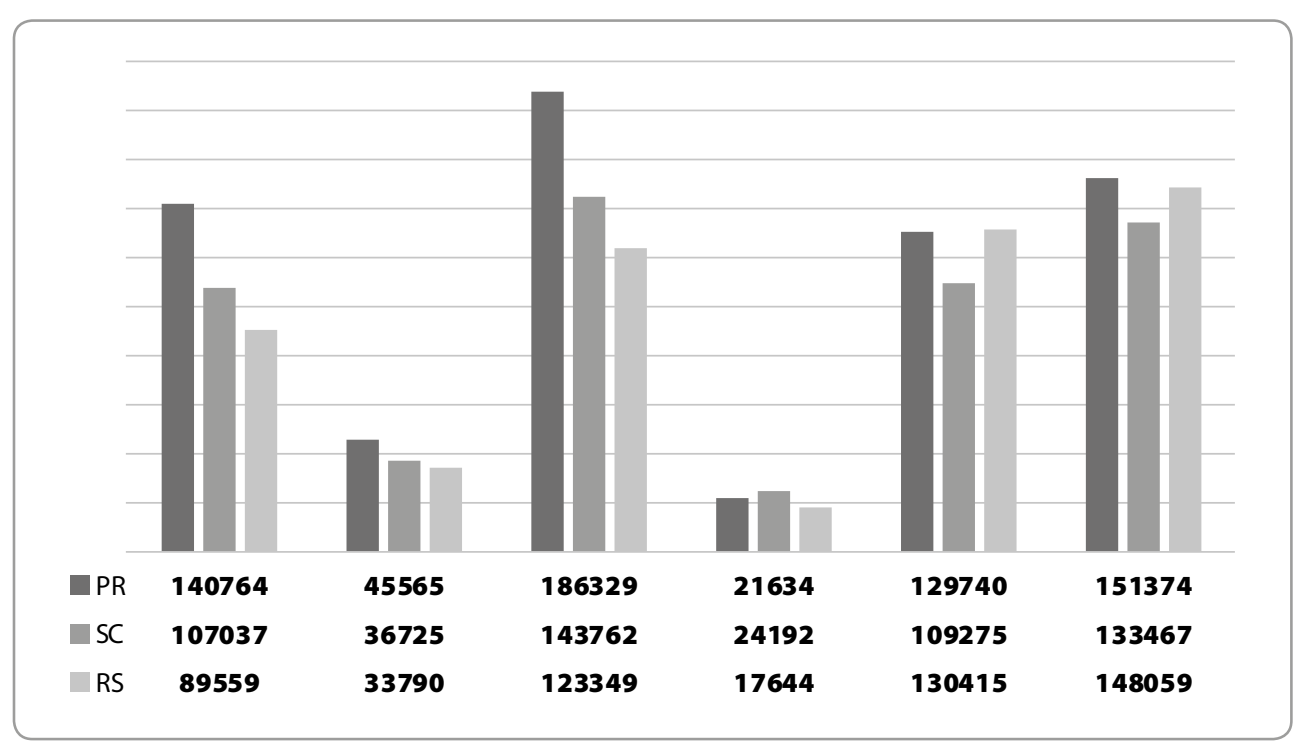

Fonte: Elaborado pelas autoras com base na Sinopse Estatística da Educação Básica 2016 (INEP, 2017).

No ensino fundamental a discrepância é grande, acentuando-se o número de matrículas em tempo parcial, em detrimento do integral, conforme demonstra o gráfico a seguir. 


\section{Gráfico 6 - Número de matrículas em TI e TP no Ensino Fundamental}

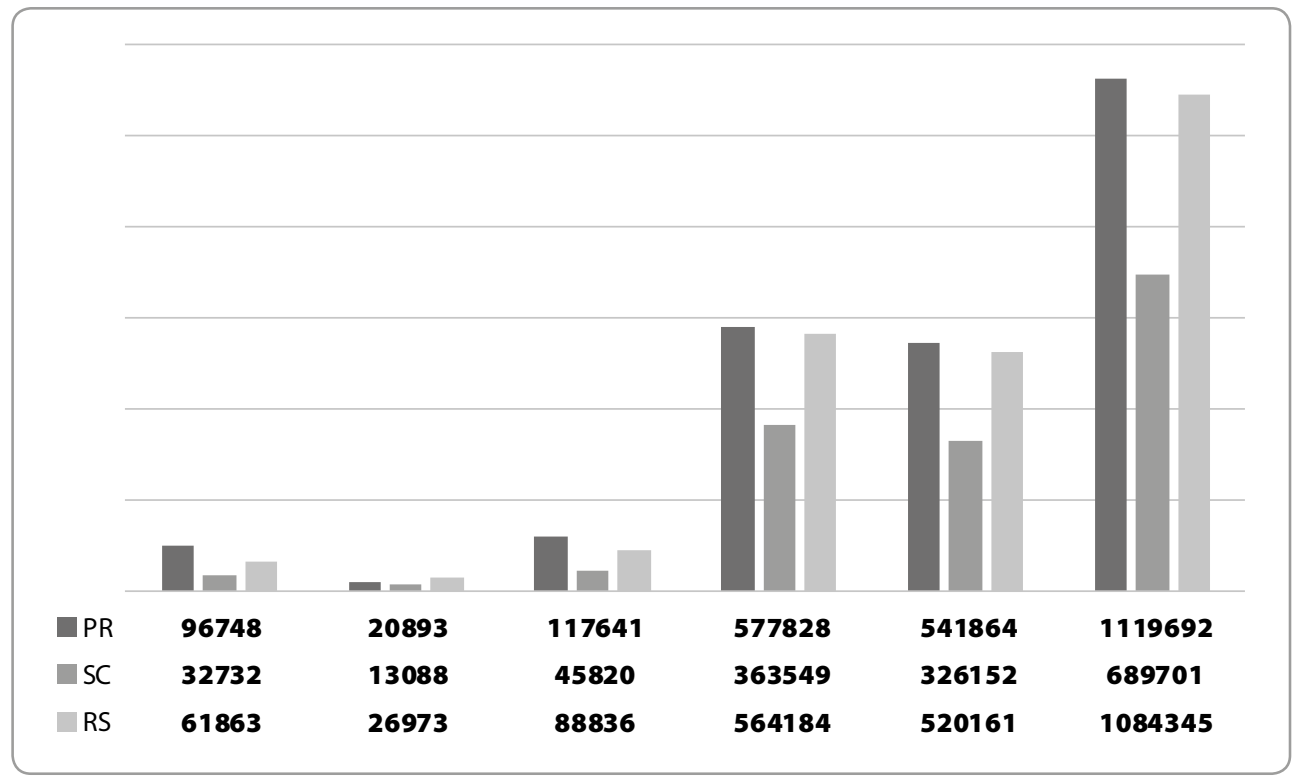

Fonte: Elaborado pelas autoras com base na Sinopse Estatística da Educação Básica 2016 (INEP, 2017).

No que se refere aos dados coletados, podemos entender que, na etapa da educação infantil, no nível creche, no estado do PR, cerca de $86 \%$ das matrículas são em tempo integral, em SC $82 \%$ e no RS 83\%. No nível da pré-escola, o valor aproximativo de porcentagem dos respectivos estados foi de: $25 \%, 25 \%$ e $20 \%$. Sendo assim, é possível afirmar que na creche, os estados já conseguem ofertar mais que a metade das vagas públicas em tempo integral, ao contrário da pré-escola em que o número de matrículas ainda é abaixo da metade do total de matrículas. Materializamos os valores na tabela a seguir. 
Tabela 2 - Porcentagem e valores das matrículas em TI na educação infantil

\begin{tabular}{|l|c|c|c}
\hline & Paraná & Santa Catarina & Rio Grande do Sul \\
\hline \multicolumn{3}{c}{ Creche } \\
\hline Matrículas em TI & 140764 & 107037 & 89559 \\
\hline Matrículas em TP & 21634 & 24192 & 17644 \\
\hline Total de matrículas (TI + TP) & 162398 & 131229 & 104203 \\
\hline$\%$ de TI na rede pública & $86 \%$ & $82 \%$ & $83 \%$ \\
\hline & \multicolumn{2}{c}{ Pré-Escola } & \\
\hline Matrículas em TI & 45565 & 36725 & 33790 \\
\hline Matrículas em TP & 129740 & 109275 & 130415 \\
\hline Total de matrículas (TI + TP) & 175305 & 145550 & 164205 \\
\hline \% de TI na rede pública & $25 \%$ & $25 \%$ & $20 \%$ \\
\hline
\end{tabular}

Fonte: Elaborado pelas autoras com base na Sinopse Estatística da Educação Básica 2016 (INEP, 2017).

Na etapa dos anos iniciais do ensino fundamental, a quantidade de matrículas em tempo integral segue a lógica da pré-escola, ou seja, de que há dificuldade em se ofertar maior tempo de escola nos anos básicos da escola formal. Essa dificuldade pode ser visualizada quantitativamente na tabela a seguir.

\section{Tabela 3 - Porcentagem e valores das matrículas em TI no ensino fundamental}

\begin{tabular}{l|c|c|c}
\hline & Paraná & Santa Catarina & Rio Grande do Sul \\
\hline & \multicolumn{2}{c}{ Anos Iniciais } \\
\hline Matrículas em TI & 96748 & 32732 & 61863 \\
\hline Matrículas em TP & 577828 & 363549 & 564184 \\
\hline Total de matrículas (TI+ TP) & 674576 & 396281 & 626047 \\
\hline$\%$ de TI na rede pública & $15 \%$ & $8 \%$ & $10 \%$ \\
\hline & \multicolumn{2}{c}{ Anos Finais } & \\
\hline Matrículas em TI & 20893 & 13088 & 26973 \\
\hline Matrículas em TP & 541864 & 326152 & 520161 \\
\hline Total de matrículas (TI+ TP) & 562757 & 339240 & 547134 \\
\hline$\%$ de TI na rede pública & $4 \%$ & $4 \%$ & $5 \%$ \\
\hline
\end{tabular}

Fonte: Elaborado pelas autoras com base na Sinopse Estatística da Educação Básica 2016 (INEP, 2017). 
Considerando os dados coletados e calculados, podemos afirmar que ambos os Estados estão equivalentes na oferta de tempo integral em todos os níveis de ensino. Isso quer dizer que há uma forte oferta no nível da creche, mas que vai caindo na medida em que os níveis escolares vão aumentando. Logo, constata-se que, após aprovação do PNE em 2014, pouco se avançou na oferta de tempo integral da escola pública na etapa da pré-escola até ensino fundamental nos estados do Sul do País. Esses valores nos levam a refletir sobre como ainda é necessário avançar nas discussões sobre a criação de uma escola de dia inteiro, que consiga, ao menos até o fim do plano vigente, ser ofertada para a metade da população escolar brasileira, sobretudo nos anos iniciais, considerando que tal etapa é fundamental para o amadurecimento dos processos de leitura e escrita das crianças.

Além disso, as questões referentes à pouca oferta de tempo integral relacionam-se com o percurso da história da educação brasileira, marcado por interesses políticos e por programas descontínuos.

\section{Considerações finais}

O discurso atual e legítimo sobre a necessidade do aumento do tempo que a criança passa na escola, subsidiado pelos objetivos de uma proposta de EI, mascara uma realidade muito mais sombria: as desigualdades escolares e o fracasso escolar são frutos de uma desigualdade social entre as crianças e jovens oriundos da classe popular e os das classes mais abastadas. Logo, o aumento do tempo da criança na escola ao mesmo tempo que representa um processo de melhoria da educação pública brasileira, também é o pagamento de uma dívida social para com as crianças e famílias das camadas populares que não possuem condições de oferecer outro tipo de educação e lazer para suas crianças fora do tempo escolar atual e oficial. Jaqueline Moll e Gesuína Leclerc (2012, p:17) nos relatam este compromisso legítimo e pontual que uma proposta de EI carrega consigo, ou seja:

Em um contexto de desigualdades econômicas, políticas e sociais, em que o acesso à ciência, à cultura e à tecnologia vincula-se ao pertencimento étnico, territorial, de classe, de gênero e de orientação sexual, a construção de uma política de educação básica de tempo integral faz parte das políticas afirmativas e de enfrentamento de desigualdades.

Segundo Moll (2012) ${ }^{11}$ a EI, no Brasil, deve ser vista como um espaço em que as crianças possam ter a possibilidade de se formar, incentivando seu protagonismo dentro do espaço escolar através de diferentes práticas e atividades pedagógicas (música, teatro, mídias) que possam guiar um encontro com os saberes tradicionais do currículo escolar, aliados à formação para a vida humana. A EI deve representar a organicidade das propostas educacionais e não se resumir a mais tempo da criança na escola. É pensar e promover uma escola que não seja reformista ou opressora, mas, ao contrário, uma 
escola que desenvolva práticas pedagógicas consolidadas e coerentes com as necessidades dos alunos.

Reconhecemos que é unânime e legítimo considerar a EI indispensável para o desenvolvimento da educação no País. Não obstante, a análise realizada reafirma um contato já feito anteriormente por diversos autores, ou seja, que o tempo que se passa na escola ou o "tempo de escola" deve ser reconhecido como uma política pública de fato. A EI no Brasil e a (re) planificação dos tempos e espaços escolares deve ser uma pauta fixa nas agendas educacionais, característica que ainda não existe, uma vez que, conforme mencionamos, tal debate é sazonal e, sobretudo, político partidário. Conforme podemos perceber, a plataforma referência dessa temática não é clara e não está atualizada.

Sendo assim, nossa reflexão se faz sobre o reconhecimento de que a pauta da EI é importante, emergente e atual, mas, ainda pouco valorizada no cenário político educacional brasileiro. Logo, é mister afirmar que será somente através dessa compreensão crítica e mudança de condição - ou seja, a EI deixar de ser projeto político e se transformar em política pública com recursos de toda natureza garantidos- que poderemos (re) significar as práticas escolares, que vem sendo e serão realizadas nas escolas públicas do País.

Recebido em: 15/08/2018 e aprovado em: 25/05/2018

\section{Notas}

1 Pode-se dizer que o primeiro movimento educacional que reuniu educadores para traçarem objetivos e metas para a educação do Brasil foram os pioneiros da Educação Nova, com o "Manifesto dos pioneiros" em 1937. Trinta anos mais tarde, em 1962, foi elaborado o primeiro PNE do Brasil se configurando como um conjunto de metas e objetivos a serem alcançadas num prazo de oito anos. Esse plano teve duas revisões uma em 1965 e outra em 1966, quando alguns aspectos como descentralização das metas, distribuição de recursos para a educação e alfabetização foram incluídos. Em 1988 houve uma nova tentativa de se elaborar um PNE que não foi atendida e, somente em 2001, a primeira lei do PNE foi elaborada como apresentamos (BRASIL, 2001). Porém, foi somente em 2009, com elaboração da Emenda Constitucional nº 59, de 11 de novembro de 2009 (BRASIL, 2009), que ficou decretado que o PNE passaria a ser um documento legal e elaborado de dez em dez anos.

2 Na época o cargo era intitulado Inspetor de Educação.

3 O grande fator que pesou sobre as organizações do Ciep veio da entrada massiva de alunos no sistema de ensino naquela época. As escolas superlotadas tiveram que reduzir as aulas (que eram numa jornada integral) para meia jornada e assim atenderem mais crianças e jovens em turnos separados. Foi a partir desse movimento, e que o governo não investiu para que estruturalmente se continuasse o trabalho em tempo integral, que os Ciep entraram em uma jornada escolar tradicional de quatro horas diárias.

4 Média de uma escola baseada no coeficiente cinco fornecida através de um sistema de avaliação nacional, realizado por alunos das três etapas da educação básica. Cada etapa passa por um exame diferenciado bem como possui sua média distinguida.

5 Ver mais no site https://novomaiseducacao.caeddigital.net/ (BRASIL, 2017). 
6 A Lei de Diretrizes e Bases da Educação Nacional (LDB) prevê a obrigatoriedade do funcionamento de 200 dias letivos repartidos em 800 horas anuais na escola (BRASIL, 1996).

7 Utilizamos o modelo de organização da cidade de Santa Maria. Contudo, esse modo de funcionamento pode variar de acordo com a escola ou município. Em zonas rurais, comunidades indígenas ou locais em que as mudanças climáticas impedem o funcionamento semanal das escolas, a organização pode ser diferenciada.

8 Realizamos um cálculo aproximativo através de regra de três simples sob a fórmula: número de escolas fornecidas pelo Observatório $=$ porcentagem fornecida logo, $100 \%$ seriam $x$.

9 Não iremos nos deter nas escolas privadas, mas salientamos que o valor com as privadas se computados não equivaleria ao valor disposto no observatório, mas, só aumentaria a diferença de escolas. Vale ressaltar que o Observatório não deixa claro se considerou, somente, as escolas públicas ou está incluído as privadas. Pela conferência, possivelmente elas não estão computadas.

10 Os valores em porcentagens foram arredondados para mais ou para menos a partir do indicador número 5 ao fim do resultado do cálculo de porcentagem: a partir de 5 arredondamento para mais e, abaixo de 5 , para menos.

11 Vídeo do II Seminário de Educação Integral - RJ, 2012. Disponível pela Secretaria Municipal de Educação de Seropédica, RJ.

\section{Referências}

ARROYO, Miguel. O direito a tempos-espaços de um justo digno viver. In. MOLL, J. MOLL. J. Caminhos da educação integral no Brasil: direito a outros tempos e espaços. Porto Alegre: Penso, 2012. p.33-45.

BRASIL. Lei $\mathbf{n}^{\circ} 9.396$ de20 de dezembro de 1996. Estabelece as diretrizes e bases para a educação nacional. Disponível em : http://www.planalto.gov.br/ccivil_03/leis/L9394.htm. Acesso em: 14 fev. 2017.

BRASIL. Lei $\mathbf{n}^{\circ} \mathbf{1 0 . 1 7 2}$, de 9 de janeiro de 2001. Aprova o Plano Nacional de Educação e dá outras providências. Brasília, 9 jan. 2001. Disponível em: http://www.planalto.gov.br/ccivil_03/leis/ leis_2001/110172.htm. Acesso em: 14 fev. 2017.

BRASIL. Resolução/CD/FNDE n⿳0 38, de 16 de julho de 2009. Ministério da Educação. Fundo Nacional do Desenvolvimento da Educação. Conselho Deliberativo. Dispõe sobre o atendimento da alimentação escolar aos alunos da educação básica no Programa Nacional de Alimentação Escolar - PNAE. Brasília: 2009b. Disponível em: http://portal.mec.gov.br/index.php?option=com_ docman\&view=download\&alias=8147-i-res038-16072009-1-pdf\&category_slug=junho-2011pdf\&Itemid=30192. Acesso em: 29 set. 2017.

BRASIL. Emenda Constitucional no 59, de 11 de novembro de 2009. Acrescenta $§ 3^{\circ}$ ao art. 76 do Ato das Disposições Constitucionais Transitórias para reduzir, anualmente, a partir do exercício de 2009, o percentual da Desvinculação das Receitas da União incidente sobre os recursos destinados à manutenção e desenvolvimento do ensino de que trata o art. 212 da Constituição Federal, dá nova redação aos incisos I e VII do art. 208, de forma a prever a obrigatoriedade do ensino de quatro a dezessete anos e ampliar a abrangência dos programas suplementares para todas as etapas da educação básica, e dá nova redação ao $\S 4^{\circ}$ do art. 211 e ao $\S 3^{\circ}$ do art. 212 e ao caput do art. 214, com a inserção neste dispositivo de inciso VI. Disponível em: http://www.planalto.gov.br/ccivil_03/ constituicao/emendas/emc/emc59.htm. Acesso em: 5 jan. 2018. 
BRASIL. Programa Mais Educação. Passo a Passo. Brasília, 2011. Disponível em: http://portal.mec. gov.br/index.php?option=com_docman\&view=download\&alias $=8168$-e-passo-a-passo-maiseducacao-18042011-pdf\&category_slug=junho-2011-pdf\&Itemid=30192. Acesso em: 29 jan. 2017

BRASIL. Lei n ${ }^{\circ} 13.005$ de 25 de junho de 2014. Aprova o Plano Nacional de Educação - PNE e dá outras providências. Brasília, 25 jun. 2014. 2014a. Disponível em : http://www.planalto.gov.br/ ccivil_03/_ato2011-2014/2014/lei/113005.htm. Acesso em: 29 jan. 2017.

BRASIL. Planejando a próxima década. Conhecendo as 20 metas do Plano Nacional de Educação. Brasília, 2014. Disponível em: http://pne.mec.gov.br/images/pdf/pne_conhecendo_20_metas. pdf. Acesso em: 29 jan. 2017.

BRASIL. Proposta de Emenda à constituição nº 241-a, de 2016. Altera o Ato das Disposições Constitucionais Transitórias, para instituir o Novo Regime Fiscal, e dá outras providências. Disponível em: http://www.camara.gov.br/proposicoesWeb/prop_mostrarintegra?codteor=1495741\&ffile name=Tramitacao-PEC+241/2016. Acesso em: 29 jan. 2017.

BRASIL. Novo Mais Educação. Disponível em: https://novomaiseducacao.caeddigital.net/ - !/ home. Acesso em: 28 abr. 2017.

CAVALIERE, Ana Maria. Tempo de escola e qualidade na educação pública. Educação e Sociedade, v.28, n.100, p.1015-1035, out, 2007. Disponível: http://www.scielo.br/pdf/es/v28n100/a1828100. Acesso em: 28 abr. 2017.

CAVALIERE, Ana Maria. Escola de tempo integral no Brasil: filantropia ou política de estado? Educação e Sociedade, Campinas, v. 35, n.129, p.1205-1222, out./dez. 2014.

CORDEIRO, Célia Maria F. Anísio Teixeira uma "visão" do futuro. Estudos avançados, v.15, n.42, p.241-258, maio/agosto. São Paulo: 2001. Disponível em: http://www.scielo.br/pdf/ea/v15n42/ v15n42a12.pdf. Acesso em: 25 abr. 2017.

INSTITUTO BRASILEIRO DE GEOGRAFIA E ESTATÍSTICAS. IBGE cidades. Disponível em: https:// cidades.ibge.gov.br/. Acesso em: 25 abr. 2017.

INSTITUTO BRASILEIRO DE ESTUDOS E PESQUISAS EDUCACIONAIS ANÍSIO TEIXEIRA. Censo Escolar. Disponível em: http://matricula.educacenso.inep.gov.br/controller.php. Acesso em: 25 abr. 2017.

INSTITUTO BRASILEIRO DE ESTUDOS E PESQUISAS EDUCACIONAIS ANÍSIO TEIXEIRA. Sinopse Estatística da Educação Básica 2016. Brasília: INEP, 2017. Disponível em: http://portal.inep. gov.br/sinopses-estatisticas-da-educacao-basica. Acesso em: 5 jan. 2018.

MIGNOT, Ana Chrystina. Escolas na vitrine: Centros Integrados de Educação Pública (1983-1987). Estudos avançados, São Paulo, v.15, n.42, p.153-168, maio/agosto. São Paulo: 2001. Disponível em: http://www.scielo.br/scielo.php?script=sci_arttext\&pid=S0103-40142001000200005. Acesso em: 25 de abril de 2017.

MOLL. Jaqueline. Caminhos da educação integral no Brasil: direito a outros tempos e espaços. Porto Alegre: Penso, 2012. 504p.

MOLL, Jaqueline; LECLERC, Gesuína de Fátima E. Educação integral em jornada diária ampliada: universalidade e obrigatoriedade? Em Aberto, Brasília, v.25, n.88, p.17-49, jul./dez. Brasília: 2012. Disponível em: http://emaberto.inep.gov.br/index.php/emaberto/article/view/2583. Acesso em: 25 de abril de 2017. 
OBSERVATÓRIO DO PNE. Meta 6. Educação Integral. Disponível em: http://www.

observatoriodopne.org.br/metas-pne/6-educacao-integral/analises/educacao-integral. Acesso em: 25 abr. 2017.

PORTUGAL, Mariana da C; SOARES, Antônio Jorge Gs; MOREL, Marcia; CAVALIERE, Ana Maria. Educação integral e educação do corpo na obra de Anísio Teixeira. Currículo sem fronteiras, [s.l], v.15, n.2, p.527-542, mai/ago, 2015. Disponível em: http://www.curriculosemfronteiras.org/vol15iss2articles/ portugal-soares-morel-cavaliere.pdf. Acesso em: 25 abr. 2017.

SAMPIERI, Roberto H; COLLADO, Carlos F; LUCIO, María del P. B. Metodologia de Pesquisa.

Traduzido por Daisy Vaz de Moraes. 5 ed. Porto Alegre: Penso, 2013.

SECRETARIA MUNICIPAL DE EDUCAÇÃO DE SEROPÉDICA. Jaqueline Moll II

Seminário de Educação Integral - RJ, 2012. Disponível em: https://www.youtube.com/ watch?v=GHjM2WBsrwE. Acesso em: 25 abr. 2017.

SOBRINHO, José A.; PARENTE, Marta Maria de A. CAIC: solução ou problema? Instituto de Pesquisa Econômica Aplicada, Brasília. Brasília, 1995. Disponível em: http://www.ipea.gov.br/agencia/ images/stories/PDFs/TDs/td_0363.pdf. Acesso em: 25 abr. 2017. 